\title{
IMPLEMENTASI SISTEM PENUNJANG KEPUTUSAN DALAM UPAYA EFEKTIFITAS PENENTUAN DAERAH PENGHASIL PENYU UNTUK KEGIATAN MONITORING PENANGKARAN PENYU PADA KAWASAN KONSERVASI PERAIRAN (KKP) KOTA PARIAMAN
}

\author{
Yanni Suherman 1), Renita Astri 2) \\ ${ }^{1}$ AMIK Jayanusa, Padang \\ ${ }^{2}$ AMIK Jayanusa, Padang \\ email: suhermanyanni@yahoo.com,rethakamal@unidha.ac.id
}

\begin{abstract}
Water Conservation Area Pariaman is now growing so rapidly along the spirit of regional autonomy and the total area allocated $11525.89 \mathrm{Ha}$ Pariaman city government, which includes the small islands of Pariaman town with its ecosystem is still relatively natural and maintained. With the conditions that exist today in the data management Breeding Centre this requires a better system. At the center of this conservation so many turtle eggs were found, but the data turtle eggs were discovered only recorded in a book and for further managed by utilizing simple applications Ms. Office Excel. At any time if needed information about where the region turtle eggs ever, how many turtle eggs have been found, the number of turtle eggs that have hatched in peangkaran and the number of hatchlings / young turtles that have been released back to the biota. For it is necessary to design a Decision Support System to process all the data turtle breeding so through this system will help in taking quick decisions, accurate and up to date so as to determine which areas are most produce turtle eggs immediately knowable to support government efforts to prevent the extinction of these animals turtle from the parties who are not responsible and the conservation of sea turtles in the city of Pariaman in particular.
\end{abstract}

Key words: Turtle, captivity, conservation, Decision Support System, preservation

\section{ABSTRAK}

Kawasan Konservasi Perairan (KKP) Kota Pariaman saat ini berkembang begitu pesat sejalan semangat otonomi daerah dan luas kawasan yang dialokasikan pemerintah kota Pariaman 11.525,89 Ha, yang mencakup pulau-pulau kecil kota Pariaman dengan ekosistemnya masih relatif alami dan terjaga. Dengan kondisi yang ada saat ini pengelolaan data di Pusat Penangkaran ini membutuhkan system yang lebih baik. Pada pusat konservasi ini begitu banyak telur penyu yang ditemukan, tetapi data telur penyu yang ditemukan ini hanya dicatat dalam sebuah buku dan untuk selanjutnya dikelola sederhana dengan memanfaatkan aplikasi Ms. Office Excel. Sewaktu-waktu jika dibutuhkan informasi tentang dimana daerah penghasil telur penyu terbanyak, berapa jumlah telur penyu yang telah ditemukan, jumlah telur penyu yang telah ditetaskan di peangkaran serta berapa jumlah tukik/anak penyu yang telah dilepas kembali ke biotanya, maka petugas KKP kesulitan memberikan informasi yang lengkap karena mereka harus melihat buku catatan dan menghitungnya kembali secara manual. Untuk itu perlu dirancang sebuah Sistem Pendukung Keputusan untuk mengolah seluruh data penangkaran penyu pada KKP Kota Priaman sehingga melalui system ini akan membantu dalam mengambil keputusan yang cepat, tepat dan up to date sehingga untuk menentukan daerah mana yang terbanyak menghasilkan telur penyu segera dapat diketahui untuk mendukung upaya pemerintah dalam mencegah kepunahan hewan penyu ini dari pihak-pihak yang tidak bertanggung jawab serta menjaga kelestarian penyu di kawasan kota Pariaman khususnya.

Kata Kunci: Penyu, penangkaran, konservasi, Sistem Penunjang Keputusan, pelestarian 


\section{PENDAHULUAN}

Saat ini populasi penyu di habitatnya mengalami penurunan cukup tajam. Salah satu penyebab populasi penyu berkurang, yakni penangkapan penyu oleh orang tidak bertanggung jawab dan maraknya perdagangan telur penyu oleh sebagian masyarakat pinggiran pantai. Berbagai upaya telah dilakukan oleh pemerintah untuk mengantisipasi penyebab dan pendorong kepunahan penyu, seperti melarang penjualan telur penyu, mengajak masyarakat untuk melakukan upaya penyelamatan penyu dan lain-lain.

Salah satu cara yang efektif dalam upaya menjaga kelestarian penyu adalah dengan melakukan proses penangkaran penyu. Salah satu pusat penangkaran penyu ada di wilayah Sumatera Barat yang merupakan salah satu propinsi yang memiliki wilayah pantai yang sangat panjang adalah Kawasan Konservasi Perairan (KKP) Kota Pariaman, tepatnya berada di Desa Apar, Kecamatan Pariaman Utara, Kota Pariaman, Sumatera Barat. Lokasinya di Jalan Syeh Abdul Arif Desa Apar Kecamatan Pariaman Utara, Sumatera Barat. Kawasan Konservasi Perairan dapat dimanfaatkan untuk berbagai kegiatan seperti penelitian, pelatihan, pendidikan lingkungan, bisnis, pariwisata, pemberdayaan ekonomi masyarakat, maupun pemanfaatan jasa lingkungan lainnya dengan tidak melupakan fungsi konservasi yang sesungguhnya.

Sesuai dengan Undang-undang

Nomor 31 Tahun 2004 tentang Perikanan, Kementerian Kelautan dan Perikanan dalam upayanya mengelola Kawasan Konservasi Perairan (KKP) terus mengembangkan pengelolaan yang dapat diterima masyarakat sekitar kawasan agar tujuan melakukan konservasi dapat berjalan optimal. Agar semua tujuan ini dapat dicapai maka perlu pengelolaan informasi serta dokumentasi yang baik agar semua informasi yang dibutuhkan untuk tujuan di atas dapat tersedia dengan cepat, tepat, up to date serta relevan dengan kebutuhan yang ada. Pada pusat konservasi ini begitu banyak telur penyu yang ditemukan, tetapi data tentang telur penyu yang ditemukan ini hanya dicatat dalam sebuah buku, begitu juga dengan penyu yang dilepas kelaut/habitat aslinya, sehingga apabila sewaktu-waktu ada tuntutan penyajian informasi baik oleh pimpinan, kelompok kunjungan wisata ataupun pendidikan yang memerlukan informasi tentang jumlah telur penyu yang ditemukan, maka petugas kesulitan menjawabnya karena mereka harus melihat buku catatan dan menghitungnya kembali secara manual.

Selain itu informasi tentang berapa jumlah penyu yang dirawat di pusat penangkaran dalam 1 tahun, serta berapa banyak pakan yang dihabiskan setiap bulannya pada penyu yang ada di pusat penangkaran juga sulit didapat. Padahal KKP kota Pariaman merupakan pusat informasi dan acuan bagi pemerintah, pemerintah daerah, pengelola dan penyelenggara serta masyarakat dalam kegiatan pemanfaatan kawasan konservasi perairan untuk pembudidayaan biota laut termasuk penyu salah satunya.

Disamping masalah di atas, Kawasan Konservasi Perairan (KKP) juga menghadapi kendala untuk mengetahui kawasan atau daerah mana yang paling banyak ditemukan telur-telur penyu setiap tahunnya dalam satu kali masa penyu bertelur dan daerah mana yang banyak mendapat ancaman baik dari binatang (predator) ataupun ulah manusia guna dilakukan pengawasan/perlindungan yang lebih dilakukan disana untuk mencegah setiap orang yang merusak sumber daya penyu tersebut. Sehingga KKP kota Pariaman selayaknya mampu bertindak sebagai penyedia informasi yang tepat dan akurat agar upaya perlindungan dan pelestarian penyu ini dapat dilakukan secara transparan dan memberikan akses kepada masyarakat untuk memperoleh informasi yang benar, jujur, dan tidak diskriminatif.

Tujuan penelitian menyediakan fasilitas pengolahan data yang terkomputerisasi sehingga dapat memberikan informasi monitoring penangkaran penyu/tukik yang lebih akurat dan dapat diakses kapanpun saat dibutuhkan dan merancang suatu sistem penunjang keputusan yang diharapkan bisa mempermudah pihak KKP dalam menentukan daerah penghasil penyu sehingga upaya penangkaran dapat lebih optimal dilaksanakan demi terjaganya kelestarian satwa penyu di wilayah perairan Sumatera Barat pada umumnya dan Pariaman khususnya 


\section{METODE PENELITIAN}

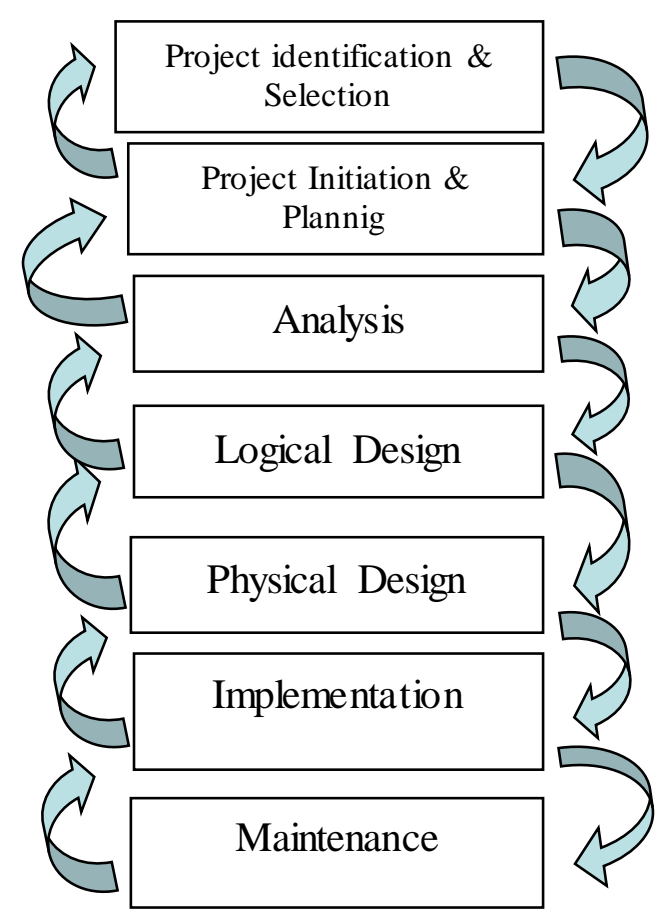

Gambar .1. SDLC dengan ke-7 phasenya

Output atau produk yang dihasilkan ditiap phase SDLC

a. Project Identification \& Selection, menghasilkan :

Perencanaan Sistem, yaitu menentukan prioritas sistem dan proyek, arsitektur dari data, jaringan, hardware, dan manajemen dari sistem informasi. Pada tahap ini akan dilakukan indentifikasi terhadap permasalahan yang ada sehubungan dengan tujuan pembangunan Sistem Penunjang Keputusan monitoring kegiatan penangkaran penyu. Untuk kegiatan ini diperlukan waktu 1 bulan.

b. Project Initiation \& Planning, menghasilkan :

Langkah terperinci atau rencana kerja untuk proyek, spesifikasi dari ruang lingkup penelitian dan syarat/bentuk sistem (high-level), tugas untuk anggota team dan sumber daya lainnya, sistem perundangan /pertimbangan. Dalam tahap ini dilakukan akan ditentukan ruang lingkup dan batasan penelitian, perencanaan sistem serta rencana pengalokasian sumber daya yang dimiliki untuk melaksanakan penelitian ini. Kegiatan ini akan memakan waktu sekitar 2 bulan dan direncanakan akan dimulai di bulan ke dua penelitian ini.

c. Analysis, menghasilkan :

Kegiatan yang diprediksi akan memakan waktu kurang lebih 2 bulan ini bertujuan melakukan penjabaran mengenai sistem yang ada termasuk masalah atau peluang yang ada yang direkomendasi untuk di perbaiki/ diatasi, ditingkatkan, atau mengganti sistem yang ada, uraian mengenai sistem pilihan dan sistem perundangan /pertimbangan untuk sistem yang terpilih. Di sini akan dilakukan studi evaluasi terhadap sistem yang sedang berjalan saat ini. Melalui kegiatan analisis ini akan dihasilkan rekomendasi perbaikan demi tercapainya tujuan penelitian.

d. Logical Design, menghasilkan :

Berhubungan dengan fungsi-fungsi, spesifikasi terperinci dari semua element sistem (data, proses, input, output). Pada tahap ini akan dilakukan perancangan terhadap fungsi-fungsi logic dari system penunjang keputusan untuk memonitoring kegiatan penangkaran penyu yang akan dibangun. Perancangan logic ini rencananya akan memakan waktu sekitar 1 bulan.

e. Physical design, menghasilkan :

Pada tahun ke dua penelitian, tahapan ini lebih bersifat teknis, spesifikasi terperinci dari semua element sistem (program, file-file, jaringan, sistem software, dll), rencana untuk teknologi baru. Tahap ini akan memberikan hasil berupa rancangan fisik berupa jenis software yang akan digunakan, tools yang akan digunakan untuk implementasi sistem serta spesifikasi hardware yang dibutuhkan. Sehingga sistem yang diinginkan bisa direalisasikan. Pelaksanaannya diprediksi sekitar 2 bulan.

f. Implementation, menghasilkan :

Code /listing program, dokumentasi, prosedur pelatihan, dan support /dukungan yang dapat diberikan. Tahap ini akan memberikan output berupa sistem yang diinginkan yaitu sebuah system Penunjang keputusan yang mampu membantu dalam 
memberikan informasi agar kegiatan penangkaran penyu dapat dilakukan secara lebih terorganisir dan akan memakan waktu kurang lebih 2 bulan.

g. Maintenance, menghasilkan :

Software versi terbaru atau dengan pembaruan untuk dokumentasi, pelatihan, support /dukungan terhadap hasil penelitian.

Fishbone Diagram

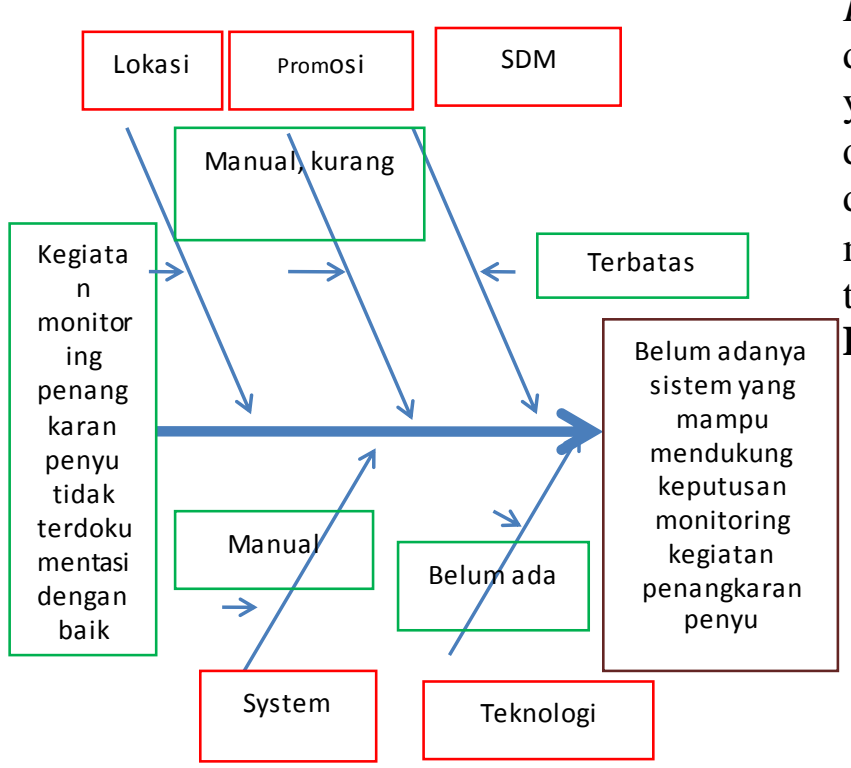

Gambar .2 : Fishbone Diagram

\section{HASIL DAN PEMBAHASAN}

\section{Kelemahan Sistem Yang Sedang Berjalan}

Berdasarkan riset yang dilakukan, terdapat kelemahan-kelemahan dan permasalahan yang menghambat jalannya proses pengolahan data mengenai telur yang didapatkan dikawasan konservasi ini, diantaranya :

1. Staff TU sulit mengetahui jumlah telur setiap data telur yang dibutuhkan secara mendadak karena data telur masih dicatat dalam buku besar.

2. Bagi Kepala UPT, kesulitan dalam mengetahui daerah yang paling banyak menghasilkan telur berdasarkan jumlah telur penyu yang dikumpulkan dan ditemukan dikawasan konservasi penyu tersebut.

Disain Sistem (Perancangan Sistem B aru)

Dalam mengatasi masalah-masalah yang ada, diperlukan perancangan sistem baru untuk mendefenisikan kebutuhan fungsional. Sistem baru yang diusulkan akan disajikan dalam bentuk rancangan fisik dan rancangan logika. Rancangan fisik akan digambarkan dengan menggunakan Aliran Sistem Informasi (ASI) sedangkan rancangan logika akan digambarkan dengan menggunakan Data Flow Diagram (DFD). Sistem yang baru diharapkan mampu mengatasi masalah yang ada pada sistem yang lama sehingga dapat menciptakan peluang beradaptasi dengan keadaan sekarang dan mampu menangani seluruh kebutuhan sistem tersebut.

\section{Disain Sistem Secara Umum}


24 Jurnal JOISIE, Volume 1, Nomor 1, Juni 2017

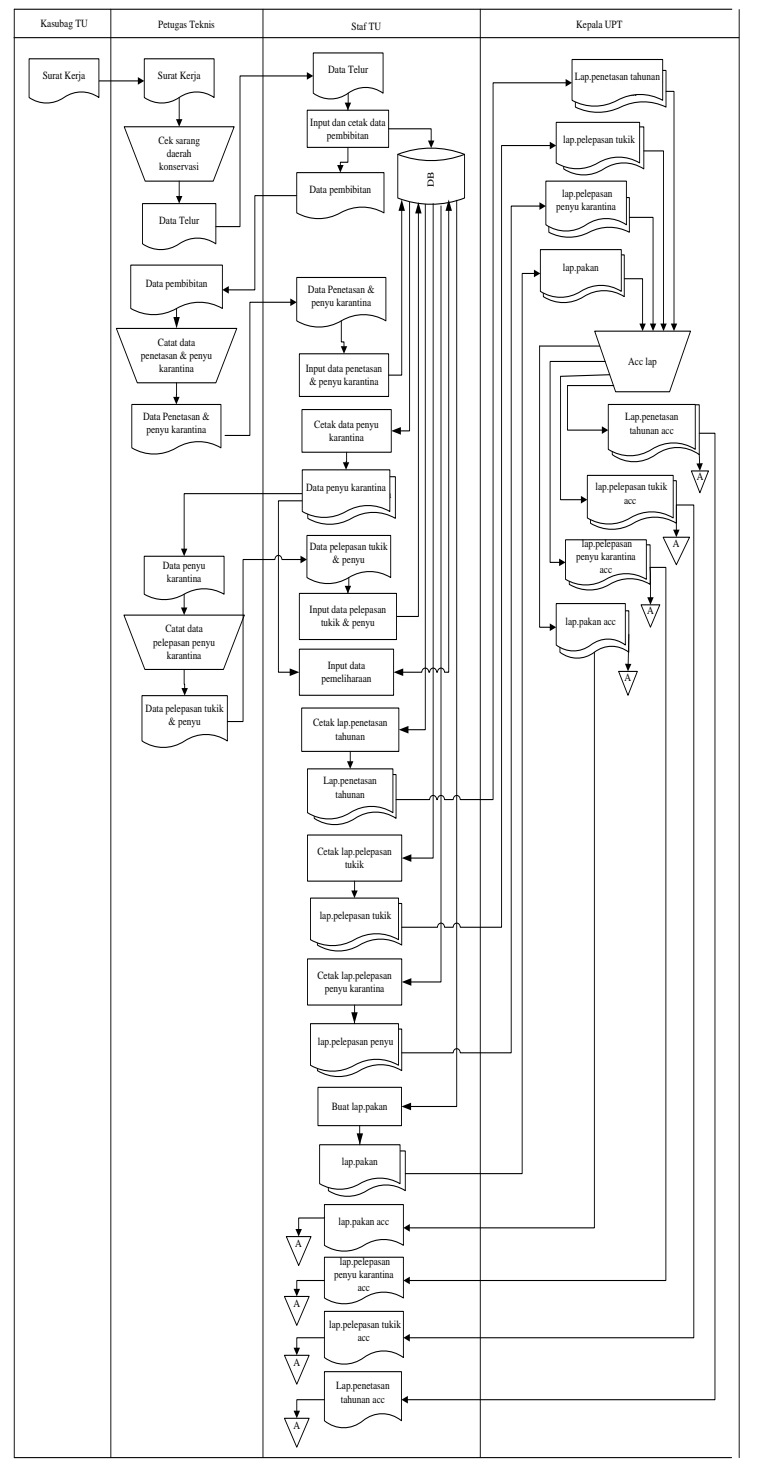

Gambar 3. Aliran Sistem Informasi Sistem Yang Di Usulkan

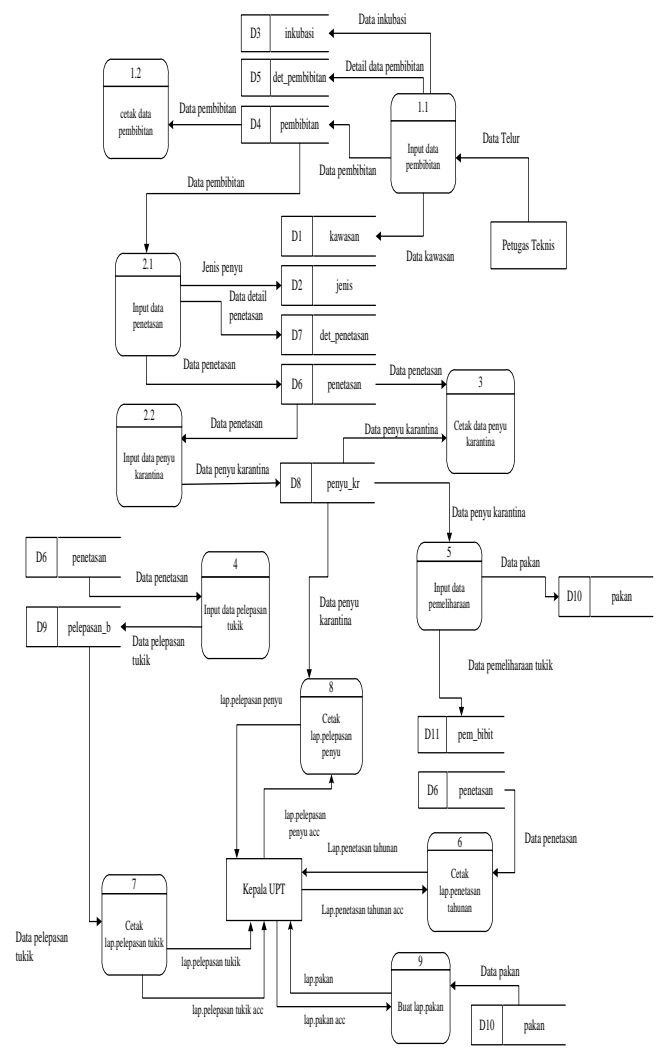

Gambar 4. Data Flow Diagram

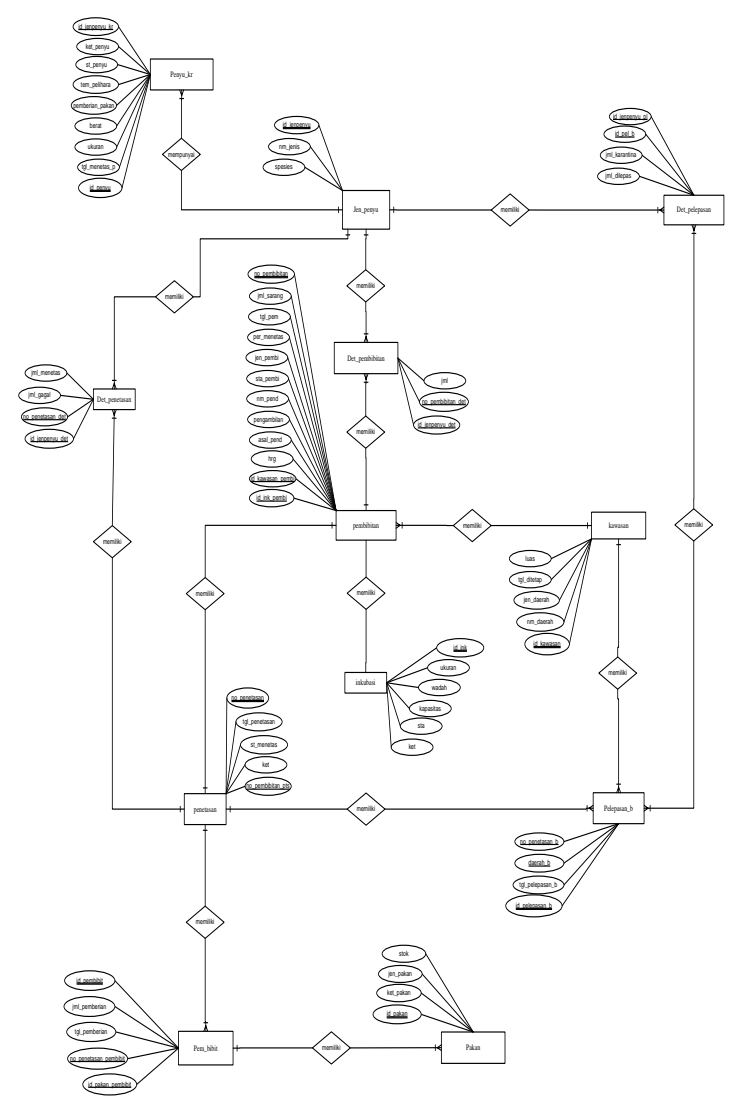

Gambar 5. Entity Relationship Diagram 
Disain Terinci

Disain terinci disebut juga dengan sistem secara fisik (physical system design) atau disain internal. Disain ini diuraikan mengenai rancangan output, rancangan input, dan rancangan file. Rancangan-rancangan ini akan menjadikan acuan di dalam perancangan sistem.

\section{Disain Output}

Desain Output Data Pembibitan

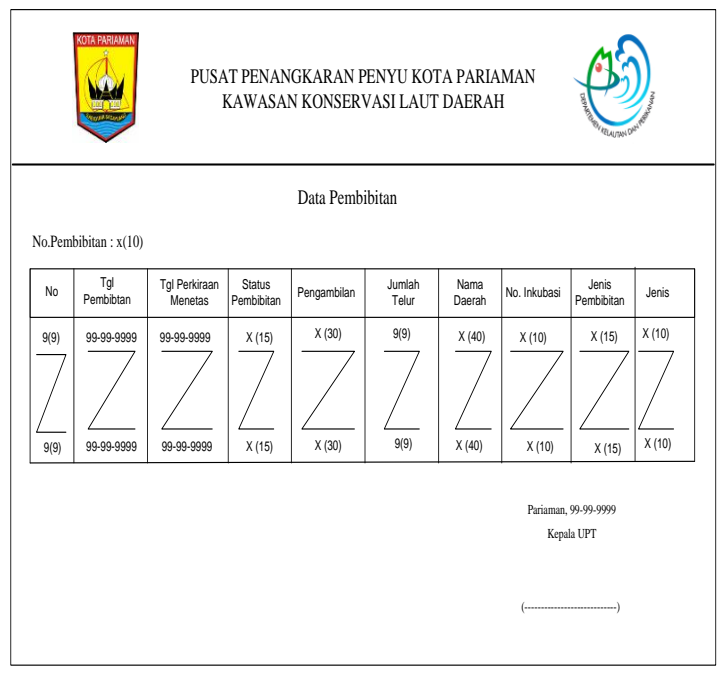

Gambar 6. Data Pembibitan

Desain Output Data Penyu Karantina

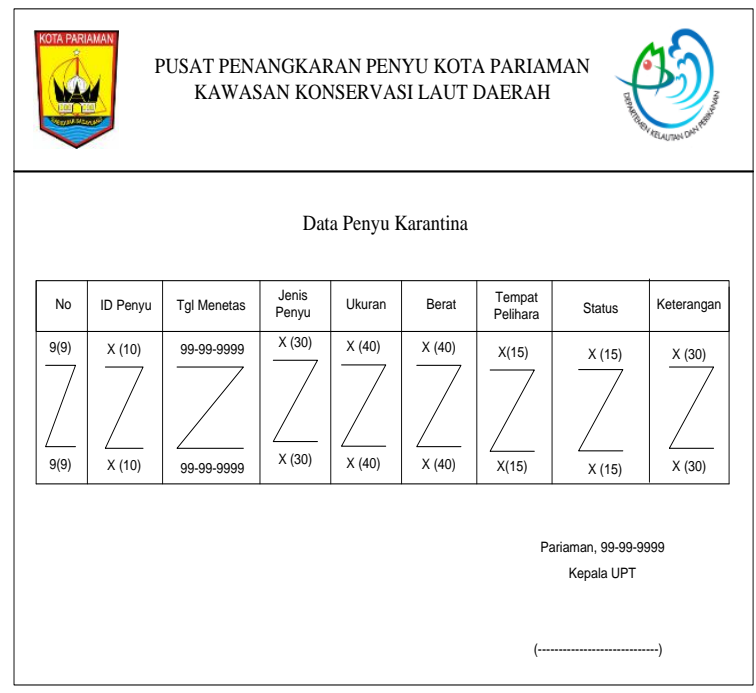

Desain Output Laporan Penetasan

Tahunan

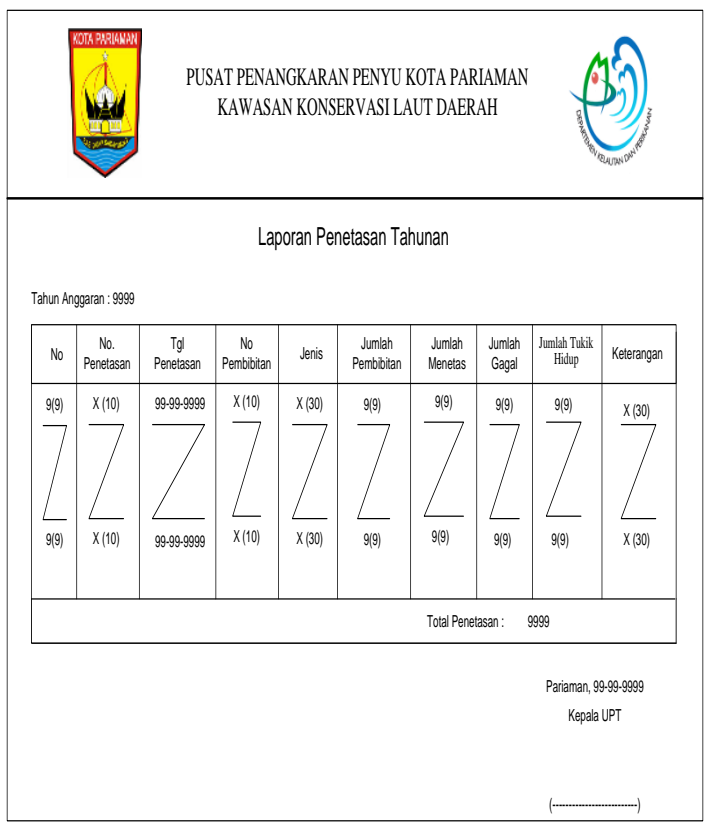

Gambar 8. Laporan Penetasan Tahunan

Desain Output Laporan Pelepasan Tukik

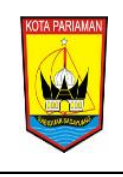

PUSAT PENANGKARAN PENYU KOTA PARIAMAN KAWASAN KONSERVASI LAUT DAERAH

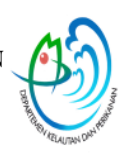

Laporan Pelepasan Tukik

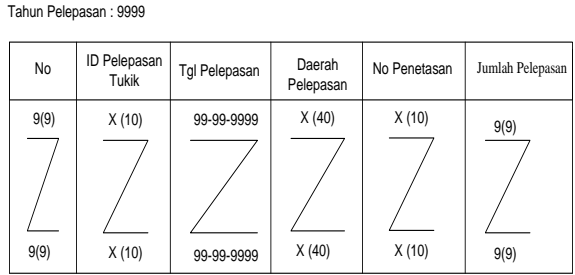

Pariaman, 99-99-9999 Kepala UPT

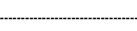

Gambar 9. Data Laporan Pelepasan Tukik

Gambar 7. Data Penyu Karantina 
Desain Output Laporan Pelepasan Penyu

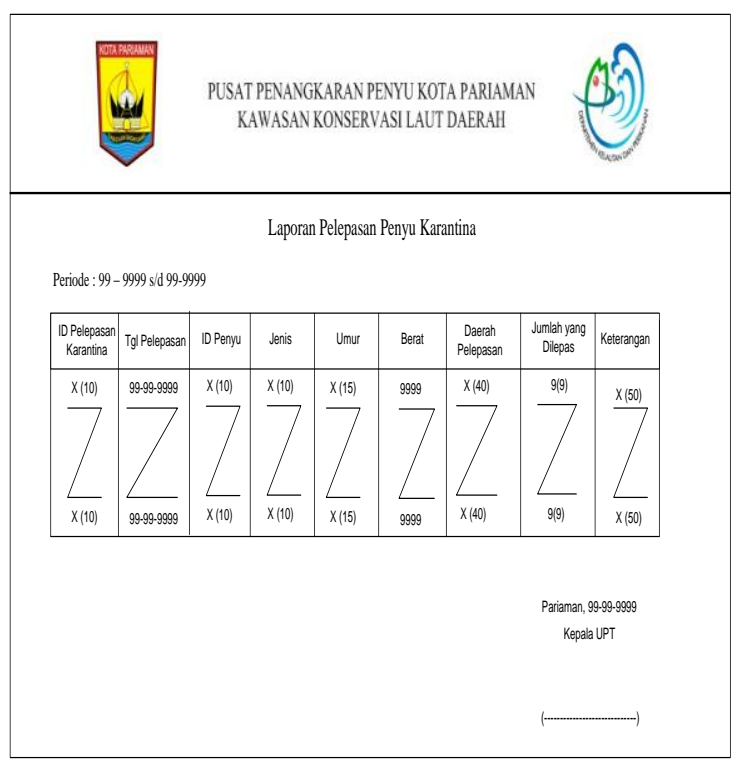

Gambar 10. Data Laporan Pelepasan Penyu

Desain Output Laporan Pakan

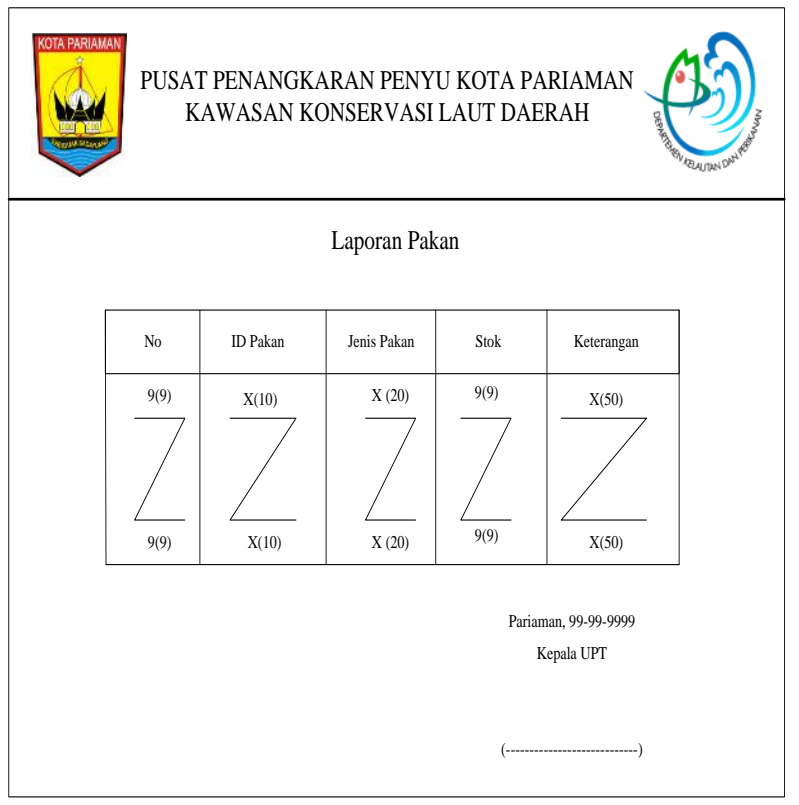

Gambar 11. Data Laporan Pakan

\section{SIMPULAN}

Dari hasil perancangan dan pembahasan yang telah dilakukan tentang Sistem Penunjang Keputusan Penangkaran Penyu pada Kawasan Konservasi Perairan (KKP) Kota Pariaman ,maka dapat ditarik beberapa kesimpulan sebagai berikut :

1. Dengan adanya Aplikasi yang mendukung sistem informasi penangkaran penyu ini, pengolahan data Penangkaran Penyu dapat dilakukan secara cepat, tepat, akurat dan akan menghasilkan informasi yang optimal tentang daerah penghasil penyu dalam mendukung upaya monitoring penangkaran penyu pada KKP Pariaman.

2. Adapun dampak positif yang akan diperoleh Sistem Penangkaran Penyu ini adalah sebagai berikut:

a. Lebih mudah dalam melakukan pengentry data

b. Lebih cepat pada pemrosesan data

c. Dapat melakukan proses yang berulang secara efisien

Pengambilan informasi dapat dilakukan sewaktu-waktu di butuhkan

\section{UCAPAN TERIMAKASIH}

Terimakasih penulis ucapkan kepada Ditjen Penguatan Riset dan Pengembangan Kementrian Riset, teknologi dan pendidikan Tinggi yang memberikan dana hibah penelitian, Lembaga penelitian dan pengabdian masyarakat AMIK Jyanusa Padang atas dukungan baik moril dan materil

\section{REFERENSI}

Davis, Gordon B, Management Information System: Conceptual Condation Structure And Development, (International Student Edition, Tokyo:1974 h:5).

Fitzgeral, Jerry, Analisis Sistem Dan Analisis Sistem Informasi : Pendekatan Terstruktur, Andi Offset:1981.

Jogiyanto, HM., Analisis dan Desain Sistem Informasi, Andi Offset, Yogyakarta: 1995.

Kusumo, Aryo Suryo Drs., Buku Latihan Pemrograman Database dengan Visual Basic 6.0, PT. Elex Media Komputindo, Jakarta: 2002. 
Suherman, 1 Implementasi Sistem Penunjang Keputusan Dalam Upaya Efektifitas Penentuan Daerah Penghasil Peny u 20-27 27 Untuk Kegiatan Monitoring Penangkaran Peny u Pada Kawasan Konservasi Perairan (Kkp) Kota Pariaman

Petroutsos, Evangelos, Pemrograman Database dengan Visual Basic 6.0 PT. Elex Media Komputindo, Jakarta:2002.

Tata Subandri, Sistem Informasi
Manajemen Berbasis Komputer. PT. Elex Media Komputindo, Jakarta, 2002 